\title{
Exergy Analysis of Internal Combustion Engine Based Cooling Cycle
}

\author{
Sandeep Kumar Kamboj*, Munawar Nawab Karimi \\ Vidya College of Engineering, Meerut, India \\ Jamia Millia Islamia Jamianagar, New Delhi 110025, India
}

\begin{abstract}
In this paper, exergy analysis of a lithium bromide water vapor absorption refrigeration system is analysed. The different alternative fuels (iso-octane, $10 \%$ ethanol blended with iso-octane \& $10 \%$ methanol blended with iso-octane) were used in a spark ignition engine. It is well known that an IC engine has an efficiency of about 35-40\%, which means that only one-third of the energy in the fuel is converted into useful work and about 60-65\% goes waste into environment. In which about $28-30 \%$ is lost by cooling water and lubrication losses, around $30-32 \%$ is lost in the form of exhaust gases and remainder by radiation, etc. The heat of exhaust gases of these alternative fuels was used to run the lithium bromide water vapor absorption system. The exergy destruction in various components of the absorption system analyzed. The results of the study shows that the maximum exergetic efficiency was for the absorption system operated with exhaust gases of isooctane followed by E10 and M10 fuels. The maximum refrigerating effect was for the iso-octane exhaust gases based absorption system followed by M10 and E10 fuels. The maximum exergy destruction was observed in the generator.
\end{abstract}

Keywords: Lithium bromide water vapour absorption system, generator, condenser, evaporator, exergetic efficiency, exergy destruction

\section{Introduction}

The vapour absorption system (VAS) uses heat energy in order to change the condition of the refrigerant required for the operation of the refrigeration cycle. In VAS, the compressor is replaced by an absorber, a pump, a generator, and a pressure reducing valve. The main advantage of this system lies in the possibility of utilizing waste heat energy from internal combustion engines, industrial plants or other sources and solar energy as the energy input. The favorable characteristic of VAS is that it requires very less amount of electrical energy to drive the solution pump. It also have fewer moving parts which means lower noise levels, higher reliability, and improved durability. Much of an internal combustion engine's heat from combustion is discarded out of the exhaust or carried away via the engine cooling water. All this wasted energy could be useful. With an absorption refrigeration system, we can utilize the exhaust heat and the heat absorbed by the engine's cooling water. This heat, which could be considered as free energy, would be enough to

\footnotetext{
* Corresponding author.

E-mail: sandeepkumarkamboj@rediffmail.com

(C) 2018 International Association for Sharing Knowledge and Sustainability

DOI: $10.5383 /$ ijtee.16.02.007
}

drive adsorption refrigeration. It is well known that an IC engine has an efficiency of about $35-40 \%$, which means that only onethird of the energy in the fuel is converted into useful work and about $60-65 \%$ goes waste into environment. In which about 28 $30 \%$ is lost by cooling water and lubrication losses, around 30$32 \%$ is lost in the form of exhaust gases and remainder by radiation, etc. By designing a generator capable of extracting the waste heat of an IC engine without any decrease in engine efficiency, a Vapour Absorption Refrigeration System can be brought to work.

Sencan et al. [1] evaluated exergy analysis of lithium bromide water absorption systems. It is concluded that the condenser and evaporator heat loads and exergy losses are less than those of generator and absorber. Maurya et al. [2] did the study of a cooling system for an automobile based vapour absorption refrigeration cycle using waste heat of an engine. Kaynakli et al. [3] did thermodynamic analysis of absorption system based on entropy generation. It was concluded that increasing generator temperature, total entropy generation of the system decreases. Entropy generation in the refrigent heat exchanger, expansion valve and solution pump is negligibly small. Sedighi et al.[4] did exergy analysis: parametric study on lithium bromide water 
absorption refrigeration systems. The result shows that a reduction in cooling water temperature caused an improvement in COP and exergetic efficiency. Khaliq et al. [5] evaluated thermodynamic performance of an industrial waste heat recovery-based trigeneration system. The energy and exergy efficiency parameters were studied using an analytical model. Zhang [6] studied an adsorption air conditioning system. Talbi et al. [7] evaluated energy recovery from diesel engine exhaust gases for performance enhancement and air conditioning. The simulation is performed using "SPICE", a well-known programme commonly used for engine performance predictions. This study examines the interfacing of the turbocharged diesel engine with an absorption refrigeration unit and estimates the performance enhancement. Mostafavi et al. [8] did thermodynamic analysis of combined diesel engine and absorption unit-turbocharged engine with inter cooling. This paper explores the utilization of the exhaust gases from a turbocharged and intercooled engine as an energy input to a vapour absorption refrigeration machine that is used primarily to cool the engine charge air in an intercooler. The influence of the engine configuration and performance parameters on the performance of an ideal system is investigated. Chua et al. [9] investigated improved thermodynamic property of $\mathrm{LiBr}-\mathrm{H}_{2} \mathrm{O}$ solution using most of experimental data. The temperature span ranges from 0 to $190^{\circ} \mathrm{C}$, while the concentrations span from 0 to $75 \%$ wt. The information's would be useful for absorption chillers. Jiangzhou et al. [10] did experimental study on locomotive driver cabin adsorption air conditioning prototype machine. It employs zeolite - water as the working pair and is powered by waste heat from exhaust gas of the internal combustion engine. Lu et al. [11] did practical experiments on an adsorption air conditioner powered by exhaust heat from a diesel locomotive with the pair zeolite water. Vicatos et al. [12] did the study a car air- conditioning system based on a refrigeration cycle using energy from exhaust gases of an internal combustion engine. It was concluded that the exhaust gases of motor vehicles have enough energy which can be utilised to drive an air conditioning system. D.R. Prajapati et al [13] studied the effect of blended fuels on specific fuel consumption at varying engine loads using CVCRM engine test rig. The experimental results shows that out of the two mustard oil blends, 20-PRM shows the lowest fuel consumption at the engine loads of $2.5 \mathrm{Kg}$ and $5.0 \mathrm{Kg}$, whereas $15-\mathrm{PRM}$ shows the lowest specific fuel consumption at the engine loads of $7.5 \mathrm{Kg}$. Z.M.Hasib et al [14] evaluated Performance characteristic analysis of small diesel engines fuelled with different blends (B20, B30, B50) of mustard oil bio-diesel. A comparison of engine performance for different blends was carried out under different operating conditions.

\section{System Description}

The schematic diagram of lithium bromide water absorption refrigeration system is shown in figure 1 . The high temperature exhaust gases from an internal combustion engine (11) enter into the generator. It is basically a container where the solution is maintained at a constant level. The exhaust pipe is passed through it and its heat is extracted in the generator. It has two exits and an inlet. From the two exits, one is for the flow of refrigerant to the condenser (7) and the other for the flow of solution back to absorber (4). The exhaust pipe passing through the generator is made of copper while the other components are made of steel. The refrigerant water vapour from the generator (7) enters into the condenser where it gets condensed into the saturated liquid by giving its heat to the cooling water. The condensate from the condenser (8) is supplied to the evaporator to compensate the water vapour formed in the evaporator. The pressure reducing valve (8-9) reduces the pressure of the condensate from the condenser pressure to the evaporator pressure. The refrigerant water at low pressure gets evaporated after taking heat from the evaporator. The lithium bromide solution has a great affinity to the water vapour because of its very low pressure. The water vapours from the evaporators (10) are being absorbed by the strong lithium bromide solution and dilute the solution and forms low concentration of lithium bromide solution. Cooling water from outside (13) is introduced into the absorber for extracting the heat so that temperature does not rise. The low concentration solution (1) is pumped to the generator through heat exchanger. In heat exchanger (2- 3), the strong solution gives its heat to the weak lithium bromide solution. The weak lithium bromide solution gets heat in generator from exhaust gases and refrigerant water gets vaporised and strong solution through heat exchanger is supplied back to the absorber. This cycle is repeated.

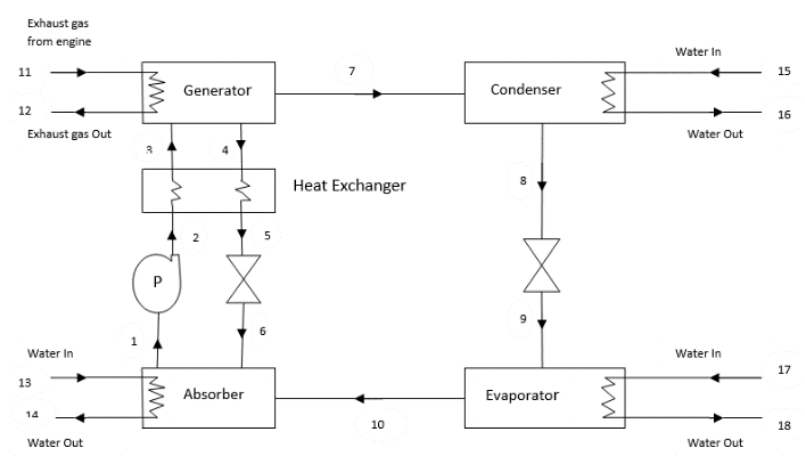

Fig. 1 Schematic diagram of $\mathrm{Li}-\mathrm{Br}$ water vapour absorption system

The specification of the spark ignition engine which was used to supply the exhaust gases to the lithium bromide water vapour absorption system is presented in Table 1 .

Table 1. Specification of the spark ignition engine

\begin{tabular}{ll}
\hline Type & $\begin{array}{l}4 \text { cylinder, } 4 \text { stroke, water } \\
\text { cooled }\end{array}$ \\
Cylinder bore and stroke & $110 \mathrm{~mm}, 87.5 \mathrm{~mm}$ \\
Compression ratio & 10 \\
Maximum power & $18 \mathrm{~kW}$ at $1800 \mathrm{rpm}$ \\
Spark variation range & $0-70 \mathrm{deg}$ btdc \\
Dynamometer & Eddy current, water cooled, \\
& with loading unit \\
Air Box & M S fabricated with orifice \\
& meter and manometer \\
Fuel tank & Capacity 60 ltr, dual \\
& compartment, with fuel \\
& metering pipe of glass \\
Calorimeter & Pipe in pipe \\
Piezo sensor & Combustion 5000 psi \\
Temperature sensor & Type RTD, PT 100 and \\
& Thermocouple, type k \\
Load indicator & Digital, range 0-50 kg, \\
& supply 230 V AC \\
Fuel flow transmitter & $\begin{array}{l}\text { DP transmitter, Range 0- 500 } \\
\text { mm WC } \\
\text { Air Flow Transmitter }\end{array}$ \\
Pressure transmitter \\
Engine cooling 40- 400 LPH; \\
Calorimeter 25-250 LPH \\
\hline
\end{tabular}




\section{Thermodynamic Model for Exergy Analysis}

A thermodynamic model on the basis of first and second law of thermodynamics is considered for analysing the exergy destruction in various components of lithium bromide water absorption system. The exergy for the steady flow system can be defined as

$E=\left(h-h_{0}\right)-$ To $\left(s-s_{0}\right)$

Where $\mathrm{E}$ is the exergy of the fluid at temperature T. The term $\mathrm{h}$ and $s$ are the enthalpy and entropy of the fluid. $h_{0}$ and $s_{0}$ are the enthalpy and entropy of fluid at the dead state.

The basic energy equations obtained from first law of thermodynamics are

$\mathrm{Q}_{\text {exhaust }}=\dot{m} \mathrm{C}_{\mathrm{p}}\left(\mathrm{T}_{11}-\mathrm{T}_{12}\right)$

Where $\dot{m}$ is the mass flow rate of exhaust gases at the exit; $C_{p}$ is the specific heat of the exhaust gases; $T_{11}$ is the exhaust gas temperature entering in the generator and $\mathrm{T}_{12}$ is the exhaust gas temperature coming out of the generator.

For generator

$\mathrm{E}_{\mathrm{Dg}}=\mathrm{To}_{0}\left[\dot{m}_{7} \mathrm{~S}_{7}+\dot{m}_{3} \mathrm{~S}_{3}-\dot{m}_{4} \mathrm{~S}_{4}+\dot{m}_{\mathrm{ex}}\left(\mathrm{S}_{12}-\mathrm{S}_{11}\right)\right]$

$\dot{m}_{3}=\dot{m}_{7}+\dot{m}_{4}$

$\dot{m}_{7} \mathrm{~h}_{7}+\dot{m}_{4} \mathrm{~h}_{4}-\dot{m}_{3} \mathrm{~h}_{3}=$ Heat supplied in the generator

$\dot{m}_{4}=\dot{m}_{7} \mathrm{X}_{3} /\left(\mathrm{X}_{4}-\mathrm{X}_{3}\right)$

$\dot{m}_{3}=\dot{m}_{7} \mathrm{X}_{4} /\left(\mathrm{X}_{4}-\mathrm{X}_{3}\right)$

Where $\mathrm{X}$ is the concentration of lithium bromide in refrigerant water

For pump

$\mathrm{W}_{\mathrm{p}}=\dot{m}\left(\mathrm{~h}_{1}-\mathrm{h}_{2}\right)$

For condenser

$\dot{m}_{7} \mathrm{~h}_{7}-\dot{m}_{7} \mathrm{~h}_{4}=$ heat carried away with the cooling water

$\mathrm{E}_{\mathrm{DC}}=\mathrm{T}_{\mathrm{o}} \dot{m}_{7}\left(\mathrm{~S}_{8}-\mathrm{S}_{7}\right)+\mathrm{mw}\left(\mathrm{S}_{16}-\mathrm{S}_{15}\right)$

For throttle valve

$\mathrm{E}_{\mathrm{DTV}}=\mathrm{T}_{0} \dot{m}_{7}\left(\mathrm{~S}_{9}-\mathrm{S}_{8}\right)$

For evaporator

$\mathrm{E}_{\mathrm{D}, \mathrm{EV}}=\mathrm{T}_{\mathrm{o}} \dot{m}_{7}\left(\mathrm{~s}_{10}-\mathrm{s}_{9}\right)+\mathrm{m}_{\mathrm{W}}\left(\mathrm{S}_{18}-\mathrm{S}_{17}\right)$

For absorber

$\mathrm{E}_{\mathrm{Dab}}=\mathrm{T}_{\mathrm{o}}\left[\dot{m}_{1} \mathrm{~S}_{1}-\dot{m}_{6} \mathrm{~S}_{6}-\dot{m}_{4} \mathrm{~S}_{4}+\mathrm{m}_{\mathrm{w}}\left(\mathrm{S}_{14}-\mathrm{S}_{13}\right)\right]$

For heat exchanger

$\mathrm{E}_{\mathrm{DHX}}=\mathrm{T}_{0}\left(\dot{m}_{3} \mathrm{~S}_{3}+\dot{m}_{5} \mathrm{~S}_{5}-\dot{m}_{2} \mathrm{~S}_{2}-\dot{m}_{4} \mathrm{~S}_{4}\right)$

Heat exchanger effectiveness

= Actual temperature difference/ Max possible temperature difference

$\mathrm{COP}=\frac{Q_{E}}{Q_{G}}=\frac{\dot{m}_{10} h_{10}-\dot{m}_{9} h_{9}}{m_{4} h_{4}+m_{7} h_{7}-m_{3} h_{3}}$

Where $\dot{m}$ is the mass flow rate and $\mathrm{h}$ is the enthalpy of the working fluid at each corresponding state point.

Exergetic efficiency
= (1- total exergy destruction/ heat supplied

If the pump work and energy losses to the atmosphere are neglected, then the sum of the generator, evaporator, condenser and absorber heat transfer must be zero. The energy balance can be written as:

$\mathrm{Q}_{\mathrm{C}}+\mathrm{Q}_{\mathrm{A}}=\mathrm{Q}_{\mathrm{G}}+\mathrm{Q}_{\mathrm{E}}$

\section{Results and Discussion}

Table 2 gives the values of thermodynamic properties and heat transfer rates of each component respectively at each state point for the iso-octane exhaust gases at $430{ }^{\circ} \mathrm{C}$ with a mass flow rate of $0.0236 \mathrm{Kg} / \mathrm{s}$. Table 3 gives the values of thermodynamic properties and heat transfer rates of each component respectively at each state point for the ethanol - iso-octane blended fuel $(10 \%$ by volume) exhaust gases at $379{ }^{\circ} \mathrm{C}$ with a mass flow rate of $0.02144 \mathrm{Kg} / \mathrm{s}$. and Table 4 gives the values of thermodynamic properties and heat transfer rates of each component respectively at each state point for the methanol iso-octane blended fuels (10\% by volume) exhaust gases at $417^{\circ} \mathrm{C}$ with a mass flow rate of $0.02184 \mathrm{Kg} / \mathrm{s}$. Table 5 gives the energy flows in various components of the system. In this analysis, calculations are done for a lithium bromide water absorption cooling cycle run by the exhaust gases of a four cylinder engine at the same speed and loads for the iso-octane, E10 and M10 fuels. For the complete analysis, the following parameters were considered. The generator, condenser, evaporator and absorber were maintained at $90,40,7$, and $40^{\circ} \mathrm{C}$. The effectiveness of heat exchanger is assumed to be 0.7 . Table 5 shows that the maximum heat transfer rate is for the generator and it is negligible for the pump. Table 6 gives the exergy destruction in all the components of the vapour absorption system.

Table 2 Thermodynamic properties of each state point for iso-octane exhaust gases at $430{ }^{\circ} \mathrm{C}$ and mass flow rate of $0.0236 \mathrm{Kg} / \mathrm{s}$

\begin{tabular}{llllll}
\hline Point & $\begin{array}{l}\mathrm{T} \\
\left({ }^{0} \mathrm{C}\right)\end{array}$ & $\begin{array}{l}\mathrm{h}(\mathrm{kJ} / \\
\mathrm{kg})\end{array}$ & $\begin{array}{l}\mathrm{s}(\mathrm{kJ} / \mathrm{kg} \\
\mathrm{K})\end{array}$ & $\begin{array}{l}\dot{m} \text { for } \\
\text { refrigerant }\end{array}$ & $\begin{array}{l}\mathrm{X}(\%) \\
\mathrm{LiBr})\end{array}$ \\
\hline 1 & 40 & 101.69 & 0.231 & 0.1577 & $57 \%$ \\
2 & 40 & 101.69 & 0.231 & 0.1577 & $57 \%$ \\
3 & 67.12 & 156 & 0.3972 & 0.1577 & $57 \%$ \\
4 & 80 & 184.962 & 0.4626 & 0.155 & $58 \%$ \\
5 & 52 & 129.68 & 0.3058 & 0.155 & $58 \%$ \\
6 & 52 & 129.69 & 0.3058 & 0.155 & $58 \%$ \\
7 & 80 & 2649.8 & 8.4848 & 0.002719 & \\
8 & 40 & 167.53 & 0.57240 & 0.002719 & \\
9 & 7 & 167.53 & 0.57240 & 0.002719 & \\
10 & 7 & 2513.7 & 8.98 & 0.002719 & \\
\hline
\end{tabular}


Table 3 Thermodynamic properties of each state point for E10 exhaust gases at $379.42{ }^{\circ} \mathrm{C}$ and mass flow rate of $0.02144 \mathrm{Kg} / \mathrm{s}$

\begin{tabular}{llllll}
\hline Point & $\begin{array}{l}\mathrm{T} \\
\left({ }^{0} \mathrm{C}\right)\end{array}$ & $\begin{array}{l}\mathrm{h}(\mathrm{kJ} / \\
\mathrm{kg})\end{array}$ & $\begin{array}{l}\mathrm{s}(\mathrm{kJ} / \mathrm{kg} \\
\mathrm{K})\end{array}$ & $\begin{array}{l}\dot{m} \\
\text { for } \\
\text { refrigerant }\end{array}$ & $\begin{array}{l}\mathrm{X}(\% \\
\mathrm{LiBr})\end{array}$ \\
\hline 1 & 40 & 101.69 & 0.231 & 0.1216 & $57 \%$ \\
2 & 40 & 101.69 & 0.231 & 0.1216 & $57 \%$ \\
3 & 67.12 & 156 & 0.3972 & 0.1216 & $57 \%$ \\
4 & 80 & 184.962 & 0.4626 & 0.1195 & $58 \%$ \\
5 & 52 & 129.68 & 0.3058 & 0.1195 & $58 \%$ \\
6 & 52 & 129.69 & 0.3058 & 0.1195 & $58 \%$ \\
7 & 80 & 2649.8 & 8.4848 & 0.0020966 & \\
8 & 40 & 167.53 & 0.57240 & 0.0020966 & \\
9 & 7 & 167.53 & 0.57240 & 0.0020966 & \\
10 & 7 & 2513.7 & 8.98 & 0.0020966 & \\
\hline
\end{tabular}

Table 4 Thermodynamic properties of each state point for M10 exhaust gases at $417^{\circ} \mathrm{C}$ and mass flow rate of $0.01977 \mathrm{Kg} / \mathrm{s}$

\begin{tabular}{|c|c|c|c|c|c|}
\hline Point & $\begin{array}{l}\mathrm{T} \\
\left({ }^{0} \mathrm{C}\right)\end{array}$ & $\begin{array}{l}\mathrm{h}(\mathrm{kJ} / \\
\mathrm{kg})\end{array}$ & $\begin{array}{l}\mathrm{s}(\mathrm{kJ} / \mathrm{kg} \\
\mathrm{K})\end{array}$ & $\begin{array}{l}\dot{m}(\mathrm{Kg} / \mathrm{s}) \\
\text { for M10 }\end{array}$ & $\begin{array}{l}\mathrm{X}(\% \\
\mathrm{LiBr})\end{array}$ \\
\hline 1 & 40 & 101.69 & 0.231 & 0.126 & $57 \%$ \\
\hline 2 & 40 & 101.69 & 0.231 & 0.126 & $57 \%$ \\
\hline 3 & 67.12 & 156 & 0.3972 & 0.126 & $57 \%$ \\
\hline 4 & 80 & 184.962 & 0.4626 & 0.124 & $58 \%$ \\
\hline 5 & 52 & 129.68 & 0.3058 & 0.124 & $58 \%$ \\
\hline 6 & 52 & 129.69 & 0.3058 & 0.124 & $58 \%$ \\
\hline 7 & 80 & 2649.8 & 8.4848 & 0.002184 & \\
\hline 8 & 40 & 167.53 & 0.57240 & 0.002184 & \\
\hline 9 & 7 & 167.53 & 0.57240 & 0.002184 & \\
\hline 10 & 7 & 2513.7 & 8.98 & 0.002184 & \\
\hline
\end{tabular}

Table 5 Energy flows (kW) in the various component of the system using iso-octane, E10 and M10 exhaust gases

\begin{tabular}{lllll}
\hline Component & Symbol & $\begin{array}{l}\text { Iso- } \\
\text { octane }\end{array}$ & E10 & M10 \\
\hline Evaporator & $\mathrm{Q}_{\mathrm{E}}$ & 6.37 & 4.91 & 5.12 \\
Absorber & $\mathrm{Q}_{\mathrm{A}}$ & 10.9 & 8.4 & 9.22 \\
Generator & $\mathrm{Q}_{\mathrm{G}}$ & 11.27 & 8.689 & 9.05 \\
Condenser & $\mathrm{Q}_{\mathrm{C}}$ & 6.74 & 5.2 & 5.42 \\
COP & & 0.566 & 0.566 & 0.566 \\
\hline
\end{tabular}

Table 6 Exergy destruction in different component of the lithium bromide vapour absorption cycle using Iso-octane, E10, M10 fuels

\begin{tabular}{lllllll}
\hline & $\begin{array}{l}\text { Generator } \\
(\mathrm{KW})\end{array}$ & $\begin{array}{l}\text { Condense } \\
\mathrm{r}(\mathrm{KW})\end{array}$ & $\begin{array}{l}\text { Evaporator } \\
(\mathrm{KW})\end{array}$ & $\begin{array}{l}\text { Absorber } \\
(\mathrm{KW})\end{array}$ & $\begin{array}{l}\text { Heat } \\
\text { Exchanger } \\
(\mathrm{KW})\end{array}$ & Total \\
\hline $\begin{array}{l}\text { Iso }- \\
\text { octane }\end{array}$ & 3.6 & 0.13 & 0.048 & 0.035 & 0.57 & 4.38 \\
E10 & 2.331 & 0.1832 & 0.0088 & 0.053 & 0.44 & 3.01 \\
M10 & 2.418 & 0.2 & 0.0078 & 0.508 & 0.449 & 3.58 \\
\hline
\end{tabular}

Figure 2 shows the exergy destruction in different component of the system along with total exergy destruction in the absorption system operated with exhaust gases of iso-octane E10 and M10 fuels. It is shown in the figure that maximum exergy destruction occurs in the generator for all the tested fuels and it is maximum for absorption system operated with exhaust gases of iso-octane. It is because of the reason that maximum heat transfer occurs in the generator and it is maximum for the iso-octane operated absorption system as shown in Table 5.The minimum exergy destruction is for the evaporator among all the components. The total exergy destruction is maximum for the absorption system operated with exhaust gases of iso-octane followed by M10 fuels. Figure 3 shows the refrigerating effect along with the exergetic efficiency for the iso-octane, E10 and M10 exhaust gases operated lithium bromide absorption system. It is shown in the figure that the refrigerating effect is higher for the isooctane exhaust gases based refrigeration system. It is because of the reason that higher amount of refrigerant water gets evaporated in the generator because of the higher exhaust gas temperature and higher mass flow rates of the exhaust gases. Further, this refrigerant water extracts more quantity of heat in the evaporator resulting in more refrigerating effect. The refrigerating effect is minimum for the E10 exhaust gases based absorption system because of less quantity of refrigerant water gets evaporated in the generator. It is because of the reason that the less quantity of heat is being supplied in the generator because of low temperature of exhaust gases. Further, less quantity of heat would be extracted in the evaporator for evaporating this water refrigerant.

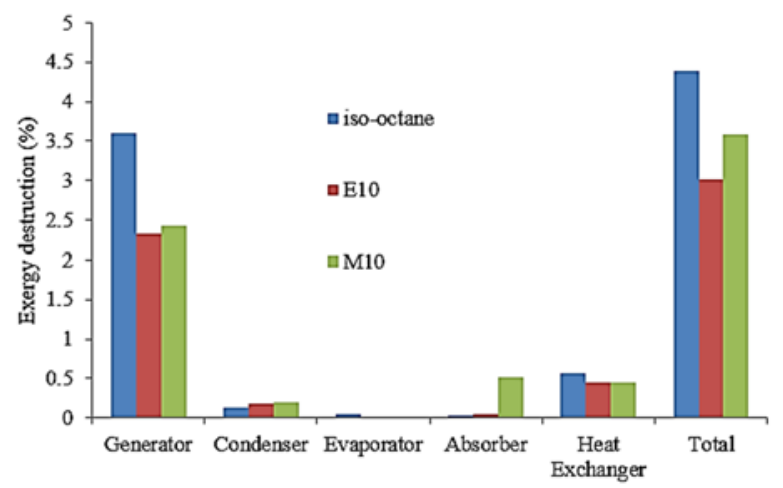

Fig. 2 Exergy destruction in different component of the system for iso-octane E10 and M10 exhaust gases

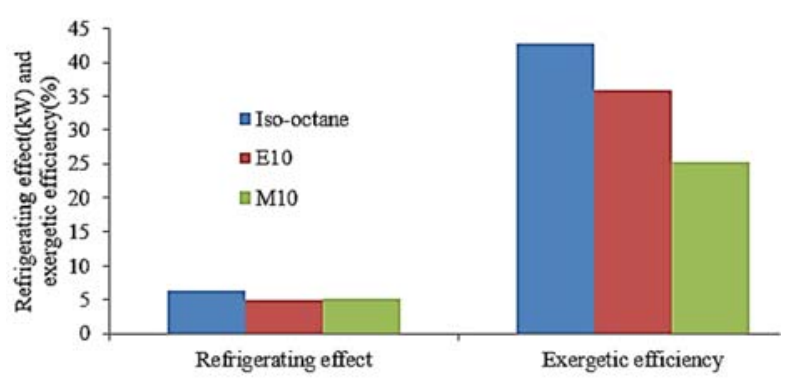

Fig. 3 Refrigerating effect and exergetic efficiency for iso-octane, E10 and M10 fuels

Figure 3 also shows the variations in the exergetic efficiency of the iso-octane, E10 and M10 based absorption system. It is shown in the figure that the exergetic efficiency is maximum for the iso-octane exhaust gases based absorption system. The exergetic efficiency depends upon the ratio of exergy destruction of the system to the exergy in to the system. Higher the ratio, lesser would be the exergetic efficiency. This ratio is lower for the iso-octane based absorption system therefore exergetic efficiency is higher and this ratio is higher for the M10 based absorption system, therefore, exergetic efficiency is lower. 


\section{Conclusion}

In this paper, a lithium bromide water absorption system is discussed depending upon the exhaust gases of iso-octane, E10 and M10 fuels at the same speed and load. The generator, condenser, evaporator and absorber temperature has been fixed. The following conclusion has been drawn from this study:

- The exergy destruction is maximum in the generator among all the components of the absorption system.

- Maximum exergy destruction in the generator is for the iso-octane based absorption system.

- The total exergy destruction is maximum for the isooctane and minimum for the E10 based absorption system.

- $\quad$ The refrigerating capacity is maximum for the isooctane and minimum for the E10 based absorption system.

- The exergetic efficiency is maximum for the isooctane and minimum for the M10 based absorption system.

\section{References}

[1] Senkan A., Kemal A.Y., Soteris A.K., Exergy analysis of lithium bromide /water absorption system: Renewable energy. 2005, 30, 645 - 657.

[2] Maurya S. K., Awasthi S., Siddiqui S. A., A cooling system for an automobile based vapour absorption refrigeration cycle using waste heat of an engine: Int. Journal of Engineering Research and Application. 2014, 4 (3), 441 - 444.

[3] Kaynakli O., Yamankaradeniz R., Thermodynamic analysis of absorption refrigeration system based on entropy generation: Current Science. 2007, 92 (4), 472 479.

[4] Sedighi K., Farhadi M., Liaghi, M. Exergy analysis: parametric study on lithium bromide water absorption systems: Institution of Mechanical Engineers Part C. 2007, 221, 1345 1351.

[5] Khaliq A., Kumar R., Dincer I., Performance analysis of an industrial waste heat-based trigeneration system: International Journal of Energy Research. 2009, 33, 737-744.
[6] Zhang L.Z., Design and testing of an automobile waste heat adsorption cooling system. Applied Thermal Engineering: 2000, 20, $103-114$.

[7] Talbi M., Agnew B., Energy recovery from diesel engine exhaust gases for performance enhancement and air conditioning: Applied Thermal Engineering. 2002, 22, 693-702.

[8] Mostafavi M., Agnew B., Thermodynamic analysis of combined diesel engine and absorption refrigeration unit--naturally aspirated engine with precooling: Applied Thermal Engineering. 1997, 17( 6), 593-599.

[9] Chua H.T., Toh H. K., Malek A., Ng K. C., Srinivasan K., Improved thermodynamic property fields of $\mathrm{LiBr}-\mathrm{H}_{2} \mathrm{O}$ solution: International Journal of Refrigeration. 2000, 23, 412-429.

[10] Jiangzhou S., Wang R. Z., Lu Y. Z., Xu Y. X., Wu, J. Y., Experimental study on locomotive driver cabin adsorption air conditioning prototype machine: Energy Conversion and Management. 2005, 46, 1655 - 1665.

[11] Lu Y. Z., Wang R. Z., Jianzhou S., Xu Y. S., Wu, J.Y., Practical experiments on an adsorption air conditioner powered by exhausted heat from a diesel locomotive: Applied Thermal Engineering. 2004, 24, $1051-1059$.

[12] Vicatos G., Gryzagoridis J., Wang, S., A car airconditioning system based on an refrigeration cycle using energy from exhaust gases of an internal combustion engine: Journal of Energy in Southern Africa. 2008, 19, 6 - 11.

[13] Prajapati D.R., Singh G. Effect of blended fuels on specific fuel consumption at varying engine loads using CVCRM engine test rig, Int. J. of Thermal and Enviromental engineering. 2013, 6 (2), 69-74.

[14] Hasib Z.M., Rahman K.A. Performance characteristic analysis of small diesel engines fuelled with different blends of mustard oil biodiesel. Int. J. of Thermal and Enviromental engineering. 2013, 6 (1), 43-48. 


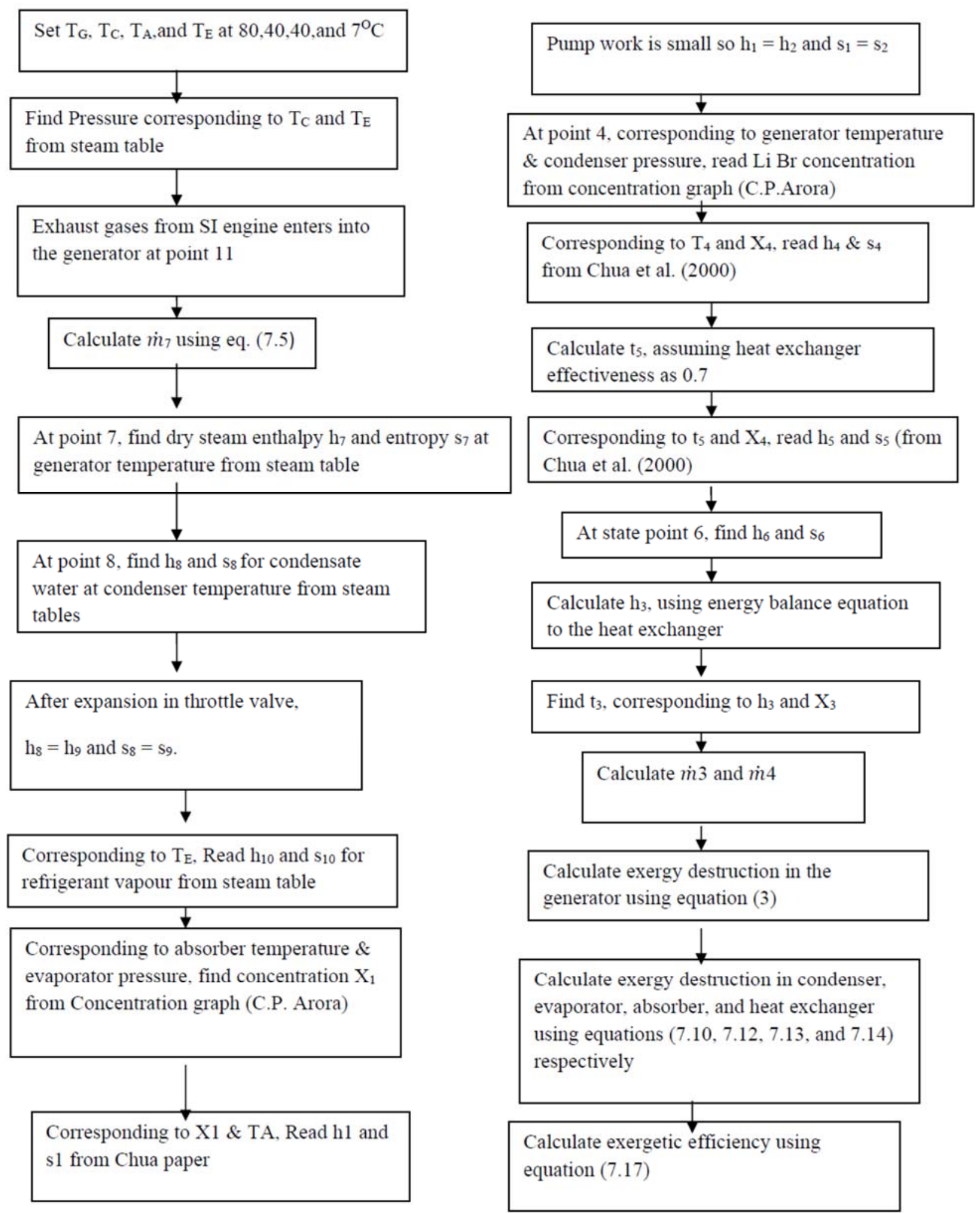

Fig. 4 Flow Chart of the process 